\title{
Gene Transfer into the Lung by Nanoparticle Dextran-Spermine/Plasmid DNA Complexes
}

\author{
Syahril Abdullah, ${ }^{1,2}$ Wai Yeng Wendy-Yeo, ${ }^{1,2}$ Hossein Hosseinkhani, ${ }^{3,4}$ \\ Mohsen Hosseinkhani, ${ }^{5}$ Ehab Masrawa, ${ }^{6}$ Rajesh Ramasamy, ${ }^{1,7}$ Rozita Rosli, ${ }^{1,2}$ \\ Sabariah A. Rahman, ${ }^{1,7}$ and Abraham J. Domb ${ }^{6}$ \\ ${ }^{1}$ UPM-MAKNA Cancer Research Laboratory, Institute of Bioscience, Universiti Putra Malaysia, 43400 UPM Serdang, \\ Selangor, Malaysia \\ ${ }^{2}$ Medical Genetics Laboratory, Faculty of Medicine and Health Sciences, Universiti Putra Malaysia, 43400 UPM Serdang, \\ Selangor, Malaysia \\ ${ }^{3}$ Center for Biomedical Engineering, Massachusetts Institute of Technology (MIT), Cambridge, MA 02139, USA \\ ${ }^{4}$ International Research Institute for Integrated Medical Sciences (IREIIMS), Tokyo Women's Medical University, 8-1, Kawada-cho, \\ Tokyo 162-8666, Japan \\ ${ }^{5}$ Center for Cancer Systems Biology, Caritas St. Elizabeth's Medical Center, Tufts University School of Medicine, MA 02135, USA \\ ${ }^{6}$ Department of Medicinal Chemistry and Natural Products, School of Pharmacy, The Hebrew University-Hadassah Medical School, \\ Jerusalem 91120, Israel \\ ${ }^{7}$ Department of Pathology, Faculty of Medicine and Health Sciences, Universiti Putra Malaysia, 43400 UPM Serdang, \\ Selangor, Malaysia
}

Correspondence should be addressed to Syahril Abdullah, syahril@medic.upm.edu.my

Received 9 February 2010; Revised 21 April 2010; Accepted 5 May 2010

Academic Editor: Jeffrey Hughes

Copyright ( 2010 Syahril Abdullah et al. This is an open access article distributed under the Creative Commons Attribution License, which permits unrestricted use, distribution, and reproduction in any medium, provided the original work is properly cited.

\begin{abstract}
A novel cationic polymer, dextran-spermine (D-SPM), has been found to mediate gene expression in a wide variety of cell lines and in vivo through systemic delivery. Here, we extended the observations by determining the optimal conditions for gene expression of D-SPM/plasmid DNA (D-SPM/pDNA) in cell lines and in the lungs of BALB/c mice via instillation delivery. In vitro studies showed that D-SPM could partially protect $\mathrm{pDNA}$ from degradation by nuclease and exhibited optimal gene transfer efficiency at D-SPM to pDNA weight-mixing ratio of 12. In the lungs of mice, the levels of gene expression generated by D-SPM/pDNA are highly dependent on the weight-mixing ratio of D-SPM to pDNA, amount of pDNA in the complex, and the assay time postdelivery. Readministration of the complex at day 1 following the first dosing showed no significant effect on the retention and duration of gene expression. The study also showed that there was a clear trend of increasing size of the complexes as the amount of pDNA was increased, where the sizes of the D-SPM/pDNA complexes were within the nanometer range.
\end{abstract}

\section{Introduction}

The success of gene therapy has largely depended upon the development of delivery vectors, which are able to efficiently and selectively deliver genes to target cells. Viral vectors are able to mediate gene transfer with high efficiency with the possibility of long-term gene expression. However, their broad use is affected by the limited size of the genetic material that can be delivered and the possibility of insertional mutagenesis [1]. In light of these concerns, nonviral gene delivery has emerged as a promising alternative. Among the variety of different materials which have been utilized in the production of nonviral vectors [2-5], polycations are considered to be a potent candidate due to their ease of preparation, purification, stability, and the capacity to modify their physicochemical properties $[6,7]$. Over the years, a significant number of cationic polymers in linear or branched configuration have been 
explored as carriers for gene delivery. These include polyL-lysine [8], polyethylenimine (PEI) $[9,10]$, dendrimers (polyamidoamine and polypropylamine) $[6,7]$, chitosan [11, 12], cationic proteins (histones, protamine, and polylysine) $[13,14]$, and diethylaminoethyl dextran (DEAE-dextran) [15]. Polycations facilitate the tight compaction of plasmid DNA (pDNA) into small and positively charged complexes, which are readily internalized via nonspecific adsorptive endocytosis by a large variety of cells [16]. Polymers such as PEI have a highly cationic-charged organic macromolecule, which contains amino nitrogen as every third atom. Due to its relatively high gene delivery efficiency $[2,17,18]$ and ready availability, branched $25-\mathrm{kDa}$ PEI has become a benchmark which other polymers are often compared with. However, the long-term biocompatibility of aminecontaining polymers remains an important issue for use in therapeutic application in vivo, as these polymers are not readily biodegradable [19].

We have previously reported on the use of nonviral gene vectors to enhance in vitro and in vivo gene transfection [20-24]. During recent years, we have been working to synthesize a new class of biodegradable polycations capable of complexing and transfecting various genes to different cell lines in relatively high yields. More than 300 different polycations were prepared starting from various natural polysaccharides and oligoamines having two to four amino groups. These cationic polysaccharides were prepared by reductive amination of the oligoamine and periodate-oxidized polysaccharides. Although most of these cationic conjugates formed stable complexes with pDNAs as determined by ethidium bromide quenching assay, only the dextran-spermine- (D-SPM- ) based polycations were found to be highly effective in transfecting various cell lines [25-31]. Dextran-spermine conjugates have also been modified with increasing amounts of polyethylene glycol chains (PEG). While non-PEGylated dextran-spermine/pDNA (DSPM/pDNA) complexes only showed reporter gene expression locally in the muscle via intramuscular delivery, their partially-PEGylated form exhibited systemic biodistribution, followed by high levels of transgene expression in organs remote from the site of injection (lungs, liver, kidney, spleen, heart, and GI tract) [28] after intravenous delivery. This phenomenon was probably attributed to the "shielding" of the polycation complexes that reduced their surface charge and minimized the plasma protein and erythrocyte aggregation [32]; therefore prolonging the circulation of the PEGylated complexes in the blood [33].

Even though intravenous delivery elicits high level of gene expression in various organs, topical delivery to the nose via direct instillation or aerosolization has greater advantages for the use in gene therapy for lung diseases as the gene transfer is targeted exclusively to the lung; thus the gene is delivered near to the area of pathology as possible. A study by Griesenbach et al. [34] has shown that intravenous administration of liposome-DNA complexes led to deposition in the alveolar region of the lung while intratracheal delivery led to transfection at the epithelial cells lining of the bronchioles. In addition, topical delivery via intranasal route enables the gene to be localized in the lungs, which allows for lower dose for treatment [35]. As it is a noninvasive route of delivery, this can possibly reduce any deposition in the other organs. Although multiple techniques for gene delivery to the lung via intranasal delivery have been developed, including the use of adenoviruses, adeno-associated viruses, lipoplex, and polyethyleneimine, all have drawbacks, including inefficiency of gene transfer, immunological responses, inflammation, nonspecificity of cell targeting, and low levels of gene expression [36, 37].

To date, no study has been performed to determine the efficacy of D-SPM polycation exclusively in the lung, via intranasal delivery. In this study, we determined the optimal conditions for gene expression in cell culture and in mouse lungs via instillation delivery of D-SPM/pDNA complexes. In addition, we also evaluated the size of the D-SPM/pDNA particle complex and its pDNA protection efficiency against a nuclease.

\section{Materials and Methods}

2.1. Preparation of Plasmid DNA. Plasmid pCIKLux expressing luciferase reporter gene was kindly provided by the Gene Medicine Research Group, Oxford University, UK and has been described by Gill et al. [38]. Plasmid phMGFP carrying green fluorescent protein (GFP) reporter gene was purchased from Promega (Madison, WI, USA). Both plasmids are under the control of CMV immediate early gene promoter and enhancer. The plasmids were replicated in the highcopy AG 1 competent cells (Stratagene, La Jolla, CA, USA), extracted and purified by EndoFree Plasmid Purification (Qiagen, Hilden, Germany). The purified plasmids were verified based on their size and pattern by restriction enzyme analysis in $1 \%$ agarose gel electrophoresis.

2.2. Preparation of $D-S P M / p D N A$ Complex. For the cell culture study, dextran-spermine (D-SPM) and pDNA complexes were prepared at various D-SPM/pDNA weightmixing ratios of 8 to 18 ( $\mu \mathrm{g}$ dextran-spermine/ $\mu \mathrm{g}$ pDNA) $(\mathrm{w} / \mathrm{w})$. The complexes were vortexed briefly and incubated at room temperature for $30 \mathrm{~min}$. prior to being used. Dextran-spermine solutions were added to $0.5 \mu \mathrm{g}$ pDNA solution, each accounting for the increasing N/P weight ratio, to Eppendorf tube containing Opti-MEM (Invitrogen, Carlsbad, CA, USA) to obtain a final volume of $200 \mu \mathrm{L}$ for each well.

For the in vivo study, D-SPM/pDNA complexes at weight-mixing ratios ranging from 14 to 18 were prepared, with the concentration of DNA kept to $10 \mu \mathrm{g}$. Once the optimal weight-mixing ratio was identified, various concentrations of pDNA were employed to yield a fixed D$\mathrm{SPM} / \mathrm{pDNA}$ ratio. The D-SPM/pDNA complex was prepared to a final volume of $100 \mu \mathrm{L}$ for dosing throughout the study. The resulting solution was vortexed briefly and allowed to stand at room temperature for $30 \mathrm{~min}$. prior to use to allow spontaneous complex formation.

2.3. Particle Size Analysis. Fresh D-SPM/pCIKLux complexes prepared to a fixed weight-mixing ratio with a varying 
concentration of pDNA were analyzed for mean particle size by using a particle size analyzer (Nanophox, Sympatec, Germany). The principle applied in this analyzer is the Photon Cross Correlation sensor allowing for the simultaneous measurement of particle size and stability in the range of approximately $1 \mathrm{~nm}$ to several $\mu \mathrm{m}$ in opaque suspensions and emulsions. D-SPM/pCIKLux complexes were prepared by using the same amount of D-SPM with varying amount of pDNAs. All the samples were dispersed in nuclease-free water, and size determinations were performed at $25^{\circ} \mathrm{C}$ in triplicates in unweighted analysis.

2.4. DNase I Protection Assay. D-SPM/pDNA complexes at ratios that showed optimal gene expression in cell culture were incubated with 2 units of DNase I (Promega, Madison, WI, USA) at $37^{\circ} \mathrm{C}$ for 15 minutes in a final volume of $10 \mu \mathrm{L}$. The digestion was halted by the addition of stop solution. The integrity of pDNA released from the complexes was assessed by $0.8 \%$ agarose gel at $75 \mathrm{~V}$.

2.5. Cell Culture. In vitro assays were performed on African green monkey kidney fibroblast (COS-7) cell line, which was obtained from American Type Culture Collection (ATCC) (Manassas, VA, USA). The COS-7 cell lines were cultured in Dulbecco's Modified Eagle's Medium (DMEM) (SigmaAldrich, St. Louis, MO, USA) supplemented with $10 \%$ fetal bovine serum (Gibco BRL, Paisley, UK), $4.5 \mathrm{~g} / \mathrm{L}$ D-glucose, $1.0 \mathrm{mM}$ sodium pyruvate, and $1.5 \mathrm{~g} / \mathrm{L}$ sodium bicarbonate (Sigma-Aldrich). The cells were kept at $37^{\circ} \mathrm{C}$ in humidified $5 \% \mathrm{CO}_{2}$ atmosphere. Subculturing was performed when the cells reached near confluency.

2.6. Transfection of Cells Grown In Vitro. COS-7 cells were seeded at a seeding density of $5 \times 10^{4}$ cells/well on a 24 -well plate and grown in $1 \mathrm{~mL} \mathrm{DMEM} / \mathrm{FBS}$ at $37^{\circ} \mathrm{C}$ in humidified $5 \% \mathrm{CO}_{2}$ atmosphere for $24 \mathrm{~h}$ for adherence. At the time of transfection, cell growth medium was aspirated, washed with PBS, and replaced with the transfection medium without serum. After $4 \mathrm{~h}$ of transfection, $1 \mathrm{~mL}$ of new complete growth medium was gently overlaid, and cells were further incubated for $48 \mathrm{~h}$ under similar conditions. Branched $25 \mathrm{kDa}$ PEI was used as positive control. Briefly, PEI/pDNA was prepared at $10: 1 \mathrm{~N}: \mathrm{P}$ ratio, and the total of $420 \mu \mathrm{L}$ of the mixture complexes in Opti-MEM (Invitrogen) was added to each well and incubated for $24 \mathrm{~h}$. The media were then exchanged for fresh complete media and further incubated for another $24 \mathrm{~h}$. After the incubation period, cells were washed with PBS and lysed by using $1 \mathrm{X}$ reporter lysis buffer (RLB) (Promega, Madison, WI, USA).

2.7. Animals. Mice were maintained under conventional housing conditions. Mice were fed with standard chow and water ad libitum and were allowed to acclimatize for at least 7 days prior to procedures being performed. All animal experiments were carried out in accordance with the Guidelines for Animal Experiments of Universiti Putra Malaysia.
2.8. Animal Dosing and Analysis of Reporter Gene Activity. Female BALB/c mice (6-8 weeks old) were anesthetized by isofluorane (Nicholas Piramal (I), Ltd., UK) inhalation until a balanced state of anesthesia was achieved. D-SPM/pDNA complexes, naked pDNA, and dextran-spermine only solutions (D-SPM) were administered to the lungs by nasal instillation during inspiration [39]. Unless stated otherwise, $100 \mu \mathrm{L}$ of either formulation was delivered into each mouse, and the animals were euthanized 2 days postadministration. Following euthanasia by cervical dislocation, the tracheas and the lungs were removed and stored at $-80^{\circ} \mathrm{C}$ in Reporter Lysis Buffer (Promega). After thawing, tissues were homogenized using Ultra-Turrax (IKA, Staufen, Germany) and the lysates were then passed through a QIAshredder column (Qiagen). The luciferase activity for both in vitro and in vivo samples was measured using a luciferase assay kit (Promega) on a GloMax 20/20 luminometer (Promega). The relative light units (RLUs) were normalized against protein concentration in the cell extracts, which was quantified using a Bio-Rad DC Protein Assay (Bio-Rad Laboratories, CA, USA).

2.9. Statistical Analysis. Distribution-free, nonparametric Mann-Whitney $U$ test was applied to compare two unpaired groups of variable whereas ANOVA parametric test was applied to multiple group comparison. Data were presented as value \pm SEM and considered to be statistically significant if $P$-values were $<.05$. Analyses were performed using SPSS for Windows, Version 15.0.

\section{Results and Discussion}

3.1. Determination of Optimal Weight-Mixing Ratio of D$S P M / p D N A$ In Vitro. The facilitated transfer of gene into various cell lines is highly dependent on the optimized culture conditions such as oxygen and nutrients supplement [40]. Thus, it is essential to evaluate the optimal weightmixing (w/w) ratio of D-SPM to pDNA, which varied from polymer to polymer beforehand for efficient transfection. As the main concern for the in vitro study was also to verify the ability of D-SPM to deliver the gene into cell, COS-7 cells ware chosen for this experiment as this cell line has been shown to be effectively transfected by D-SPM previously in [30]. In this study, the cells were transfected with $0.5 \mu \mathrm{g}$ of pCIKLux complexed in a serum-free media with different amounts of dextran-spermine. Gene transfection efficiency was measured as a function of D-SPM/pDNA weight-mixing ratio and expressed as relative light unit (RLU) normalized to total cells protein.

As shown in Figure 1, reporter gene activity was negligible at weight ratio of 8 and 10 . However, D-SPM/pDNA was able to promote transfection in weight-mixing ratios ranging from 12 to 18 , with maximum level of expression measured at weight-mixing ratio of 12 and 14 . At this range, nearly $2.9 \times 10^{6} \mathrm{RLU} / \mathrm{mg}$ protein was obtained, which was significantly higher than the established polycation transfection agent, PEI $\left(1.4 \times 10^{6} \pm 3.2 \times 10^{5} \mathrm{RLU} / \mathrm{mg}\right.$ protein $)$. 


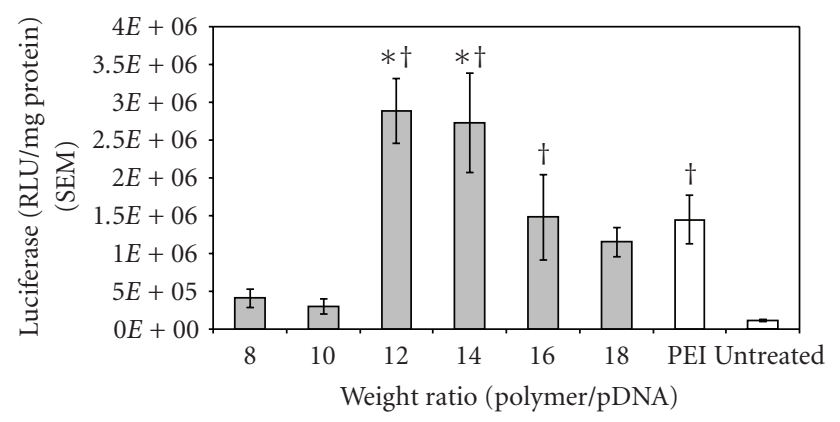

Figure 1: Transfection efficiency of D-SPM/pCIKLux complex at various weight-mixing ratios with $0.5 \mu \mathrm{g}$ pCIKLux in COS-7 cells. PEI was used as the positive control. Luciferase expression was measured as RLU/mg protein after $48 \mathrm{~h}$ posttransfection in serumfree condition. Luciferase expressions significantly higher than PEI are denoted by asterisks $\left(^{*}\right)(P<.05)$ while from untreated are denoted by dagger $\left(^{\dagger}\right)(P<.05)$. Data are presented as mean $\pm \mathrm{S}$. E. $\mathrm{M}$ of experiments conducted in triplicate.

Increasing the w/w ratio above 14 did not improve the transfection efficiency.

To ascertain that the transfection ability of the dextranspermine polycation conjugates was not plasmid or reporter gene-specific, we performed transfection with another plasmid, phMGFP, following similar protocols described above. Ratio ranging from 12 to 16 was chosen for this study as they exhibited relatively high gene expression previously. Expression of the reporter gene was estimated using an inverted fluorescent microscope (Figure 2). GFP expression was detectable in cells transfected with all ratios of DSPM/pDNA, but their transfection efficiencies seemed to be lower when compared to $\mathrm{PEI} / \mathrm{pDNA}$. The transfection efficiency was further confirmed by determining percentage of GFP-positive cells under flow cytometry (Figure 3). This quantitative analysis revealed that $13.37 \%, 11.52 \%$, and $7.61 \%$ out of 10,000 cells expressed GFP following transfection by D-SPM/pDNA at ratio 12,14 , and 16 , respectively. These percentages of cells expressing GFP were higher than the untreated $(0.34 \%)$ and naked pDNA $(3.84 \%)$ but lower than PEI/pDNA (15.26\%). These results support the fluorescence microscope observation.

Interestingly, dextran-spermine when complexed with luciferase expressing plasmid showed significantly higher gene expression when compared to PEI, but not with the GFP expressing plasmid. This discrepancy could be explained by the different strength of electrostatic interaction between the DNA helices of each plasmid and the grafted spermine, which may play a significant role in the efficiency of cell transfection. Therefore, although D-SPM was able to deliver different pDNAs into the cells effectively, the reporter gene activity might rely on the nature of the plasmid construct.

\subsection{Characterizations}

3.2.1. Effect of DNase Treatment on pDNA Encapsulated by D$S P M$. Ideally, a vector should be able to encapsulate pDNA efficiently under harsh environment conditions to enable
TABLE 1: Particle size of D-SPM/pDNA as a function of the pDNA amount loaded to D-SPM at ratio 16 , determined by Nanophox particle size analyzer.

\begin{tabular}{lcc}
\hline Sample & $\begin{array}{c}\text { Dextran-spermine/pDNA complex at } \\
\text { different amount of DNA (Ratio 16) }\end{array}$ & Size (nm) \\
\hline 1 & $15 \mu \mathrm{g}$ & 52.44 \\
2 & $20 \mu \mathrm{g}$ & 68.85 \\
3 & $25 \mu \mathrm{g}$ & 94.31 \\
4 & $30 \mu \mathrm{g}$ & 115.49 \\
\hline
\end{tabular}

longer retention time to allow more uptake of the pDNA by the cells. Efficient encapsulation by the vector is vital as the slow mobility of pDNA in cytoplasm has made it to become an easy target for the $\mathrm{Ca}^{2+}$-sensitive cytoplasmic nucleases nucleases which may restrict the half-life of plasmid DNA [41]. Therefore, to mimic the environment in the lungs with the presence of nucleases, D-SPM/pCIKLux complexes prepared at ratio 14,16 , and 18 , containing $4 \mu \mathrm{g}$ pDNA, were treated with DNase I to evaluate the protection level conferred by D-SPM to the pDNA.

Gel electrophoresis results indicate that the D-SPM at all ratios tested was able to form complexes with the pDNA, shown by the immobility of DNA to move from the well (lane 2, 4, and 6) (Figure 4). While free pDNA was completely digested by the DNase (lane 9), D-SPM encapsulated pDNA at all ratios was partially protected from degradation (lane 3, 5, and 7). D-SPM/pDNA at ratio 16 conferred maximum protection to the pDNA from DNase I degradation where brighter DNA was observed in the well (lane 5) when compared to the DNase I treated D$\mathrm{SPM} / \mathrm{pDNA}$ at other ratios. Taken together, this study shows that the D-SPM/pDNA complexes could only minimally protect the pDNA from the effect of DNase I.

\subsubsection{Effect of Increasing the Amount of DNA on the Complex} Size. Prior to the in vivo study, it is important to know the size of the complexes as smaller size gene carrier has been shown to be capable of escaping the clearance effect of the reticuloendothelial system although it has longer retention time in the system circulation [42-45]. Previous studies by Kaul and Amiji [46] also noted the importance of small size gene carrier in order to avoid the uptake by alveolar macrophages.

The physical characteristic of D-SPM/pDNA by the size measurement was carried out at a fixed weight-mixing ratio of D-SPM/pDNA complex at 16 by changing the pDNA concentrations $(15,20,25$, and $30 \mu \mathrm{g}$ pDNA) only. At the concentration of 15,20 , and $25 \mu \mathrm{g}$ of pDNA, the mean diameter was measured at 52.44,68.85, and $93.41 \mathrm{~nm}$, respectively. The complex loaded with $30 \mu \mathrm{g}$ pDNA resulted in the largest complex size with a mean diameter of $115.49 \mathrm{~nm}$. The study showed that there was a clear trend of increasing size of the complexes as the amount of pDNA was increased (Table 1). These results may be explained by the electrostatic repulsions presence between the positively charged D-SPM and the increasing amount of negatively charged pDNA, 


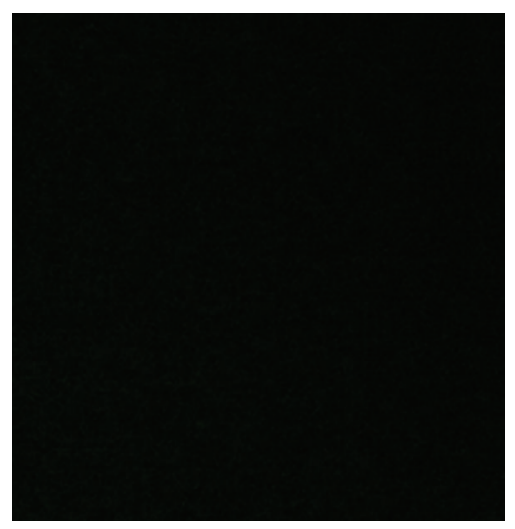

(a)

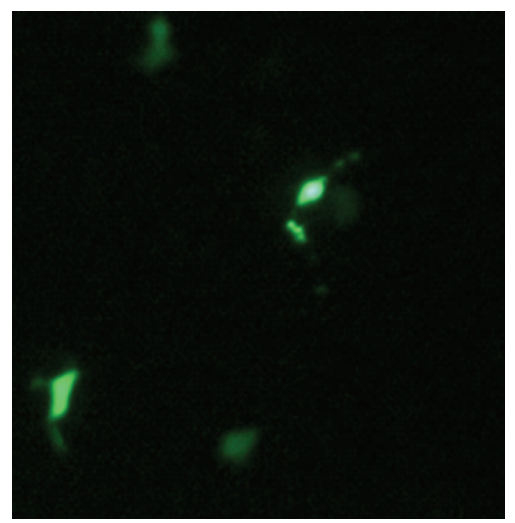

(d)

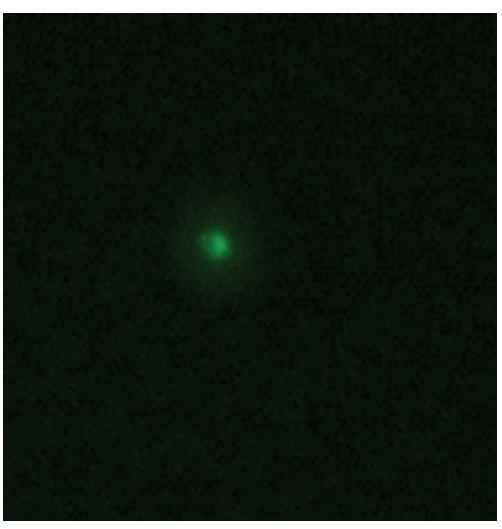

(b)

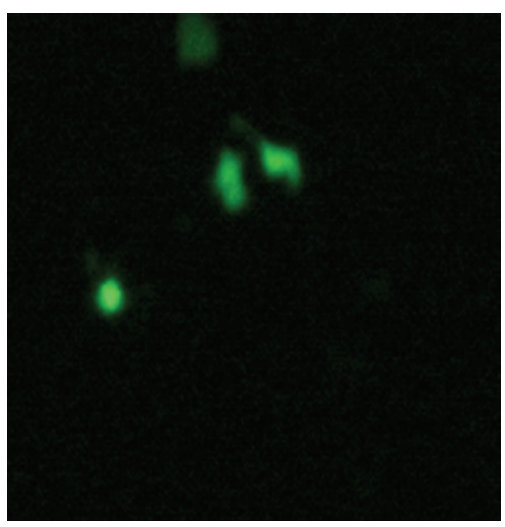

(e)

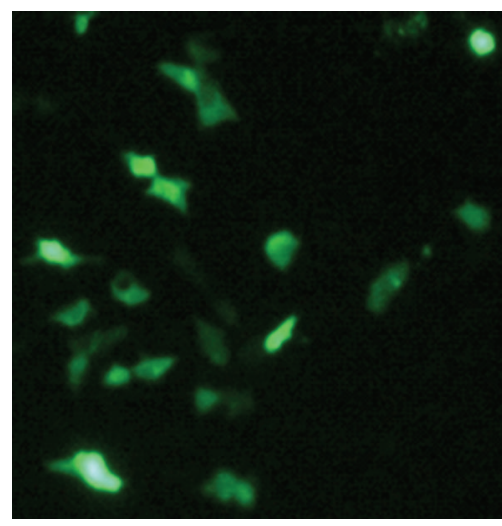

(c)

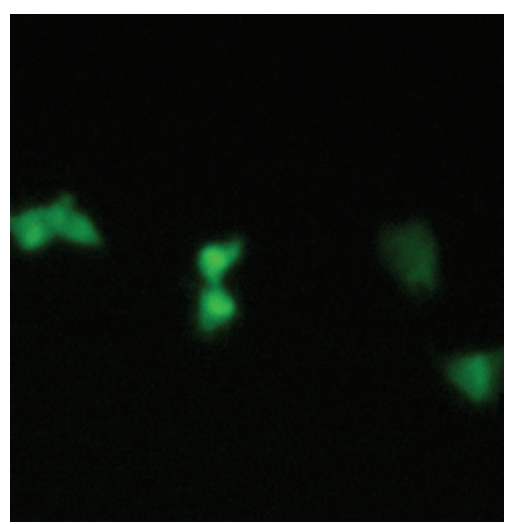

(f)

FIGURE 2: Fluorescent microscopy of GFP expression in COS-7 cell lines transfected with different gene carriers. Fluorescent cells were visualized at $48 \mathrm{~h}$ post-transfection. (a) Untreated, (b) naked DNA, (c) PEI/phMGFP, (d) D-SPM/phMGFP at ratio 12, (e) D-SPM/phMGFP at ratio 14 , and (f) D-SPM/phMGFP at ratio16. (Magnification $\mathrm{x} 10$ ).

which caused the formation of less compact complexes [31]. The overall results indicate that the sizes of the complexes 6 prepared in this study were in a nanometer range. This was in concordance with the observation by Hosseinkhani and Tabata [47], where it was reported that the D-SPM/pDNA prepared was in a nanometer size, although a larger bp size of pDNA was used to prepare the complex compared to the pDNA size used in this study. Considering that the amount of pDNA influences the size of the complex, this analysis provides a guideline for the determination of the range of the pDNA amount to be used to obtain a maximal reporter gene expression in mouse lungs in the following study.

\subsection{Determination of Optimal Weight-Mixing Ratio and} Amount of $p D N A$ of D-SPM/pDNA for Maximal Reporter Gene Expression in Mouse Lungs. We further evaluated the weight-mixing ratio of the D-SPM/pCIKLux complexes that would give the most efficient gene delivery in mouse lung at day 2 postadministration. The BALB/c mice were instilled intranasally with $10 \mu \mathrm{g}$ pCIKLux complexed with different amount of dextran-spermine to give D-SPM/pDNA weight-mixing ratio ranging from 14 to 18 . Intranasal delivery of the naked pDNA and D-SPM controls exhibited background reading of the naïve mice $(44.34 \pm 4.51 \mathrm{RLU} / \mathrm{mg}$ lung protein) (Figure 5). Similar readings were observed with D-SPM/pDNA complex at weight-mixing ratios of 14 and 15. The maximal reporter gene expression (91.23 \pm $30.18 \mathrm{RLU} / \mathrm{mg}$ lung protein) was observed at weight-mixing ratio of 16 with almost 2 -fold level of reporter gene expression in comparison to naked DNA. Unfortunately, the value was not statistically significant. No further improvement of reporter gene activity was observed with the increase ratio of the polycation.

To evaluate whether pDNA concentration influences the maximal transfection efficiency of the D-SPM at weightmixing ratio of 16 , mice were intranasally instilled with D-SPM/pDNA complexes containing varying amount of pCIKLux. The weight-mixing ratio of D-SPM/pDNA was fixed to 16, and the amount of pDNA administered was varied from $9.5 \mu \mathrm{g}$ to $17.5 \mu \mathrm{g}$ per mouse. Figure 6 shows the average luciferase activities in the mice lungs at 2 days postadministration. At pCIKlux concentration of $9.5 \mu \mathrm{g}$ and $11.5 \mu \mathrm{g}$, the reporter gene expression levels were similar to the background level exhibited by the untreated mice. Maximum level of reporter gene expression was detected 


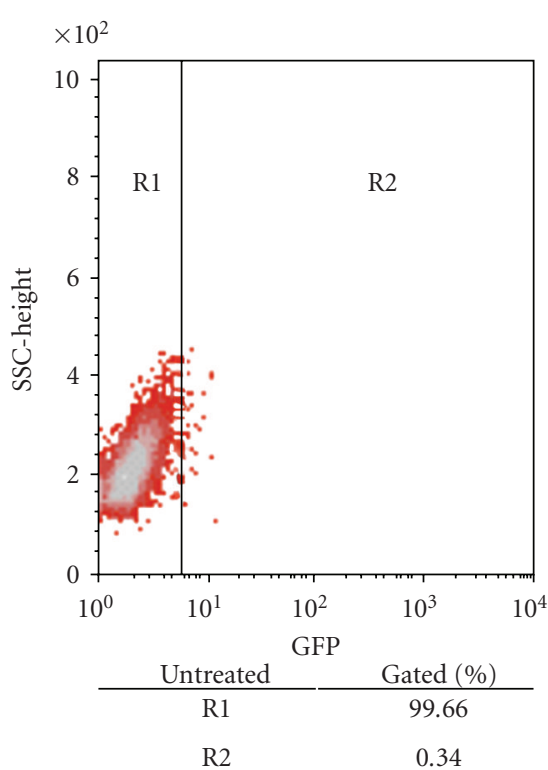

(a)
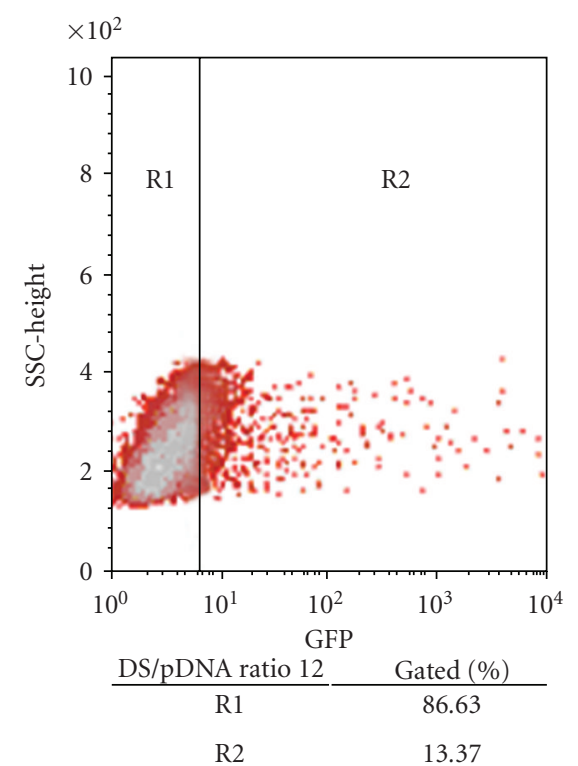

(d)

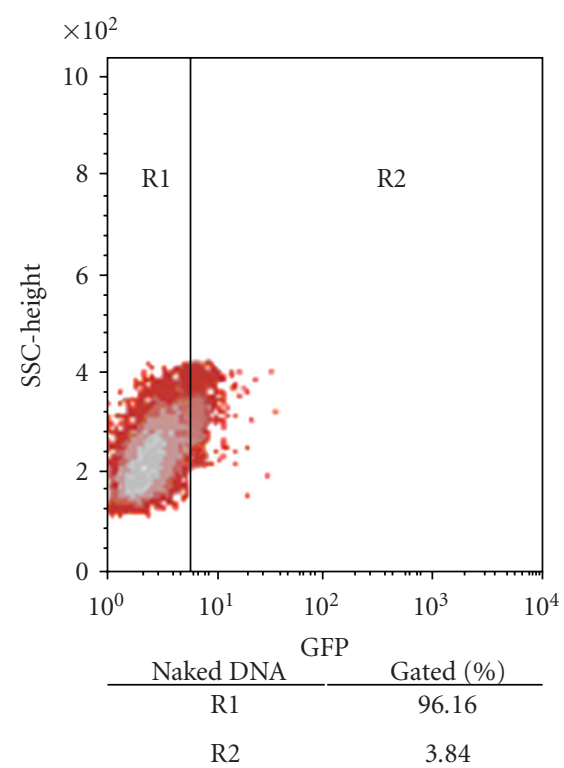

(b)
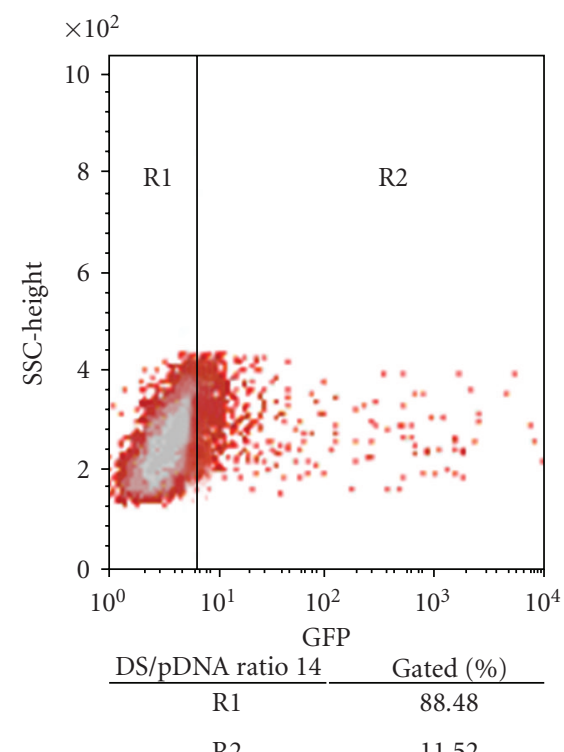

(e)

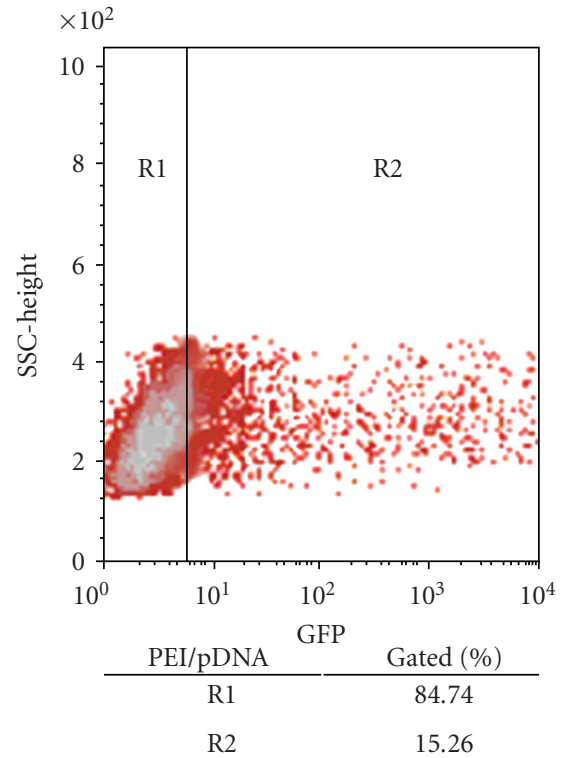

(c)

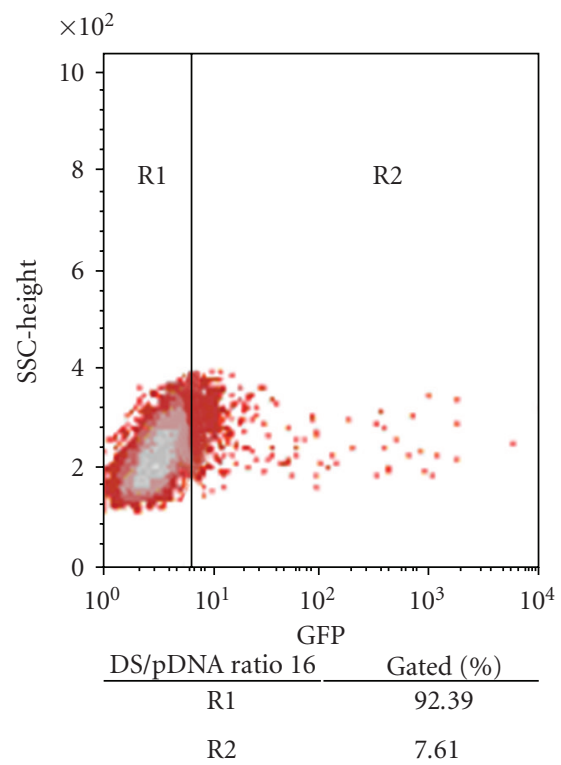

(f)

FIGURE 3: Side scatter (SSC) versus GFP fluorescent dot plot of transfected COS-7 cells showing positions of GFP-negative (R1) and GFPpositive (R2) population with the percentage gated of GFP-positive cells using flow cytometry analysis by using different gene carriers. Gene expression was measured at $48 \mathrm{~h}$ post-transfection. (a) Untreated, (b) naked DNA, (c) PEI/phMGFP, (d) D-SPM/phMGFP at ratio 12, (e) D-SPM/phMGFP at ratio 14, and (f) D-SPM/phMGFP at ratiol6.

from mice administered with $13.5 \mu \mathrm{g}$ pCIKLux. At this amount, the mean reporter gene activity was monitored at $158.1 \pm 79.6 \mathrm{RLU} / \mathrm{mg}$ lung protein, approximately 3 -fold higher when compared to the untreated group. However, increasing the amount of pCIKLux delivery beyond $13.5 \mu \mathrm{g}$ did not show any improvement in the level of reporter gene expression. It has been demonstrated that following intramuscular injection of D-SPM/pDNA, the highest level of gene expression was observed with $50 \mu \mathrm{g}$ pDNA delivered per mouse [28]. Nevertheless, in our current study, we did not see any improvement in the level of gene expression with $50 \mu \mathrm{g}$ of pDNA administered to the mouse via instillation delivery (result not shown).

Even though the D-SPM/pDNA transfection conditions which yield the maximum level of reporter gene expression in the mouse lung have been identified, this value was considered as a moderate increase from the level exhibited by the untreated animals. There are several possible explanations for this unexpectedly modest level of the luciferase activity in vivo. As pointed out by Hosseinkhani et al. [28], 


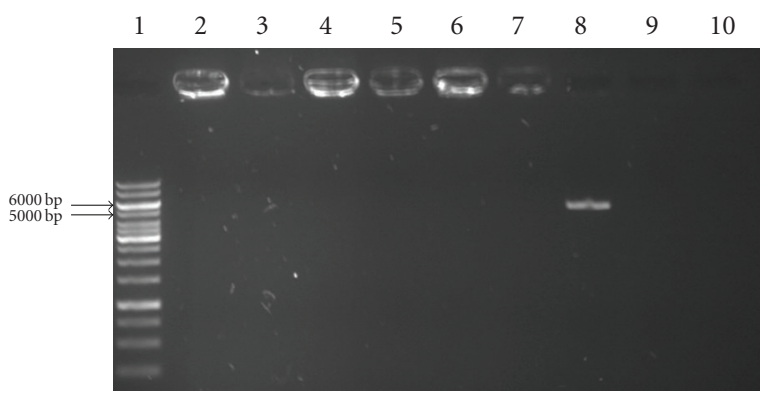

Figure 4: Agarose gel electrophoresis of D-SPM/pDNA complex at different ratios following DNase treatment. Lane 1: $1 \mathrm{~kb}$ DNA ladder; 2, 4, and 6: D-SPM complexes at ratio 14, 16, and 18, respectively; 3,5 , and 7: D-SPM/pDNA complexes at ratio 14,16 , and 18, respectively, treated with DNase I; 8: free pDNA; 9: free pDNA treated with DNase I; 10: D-SPM only.

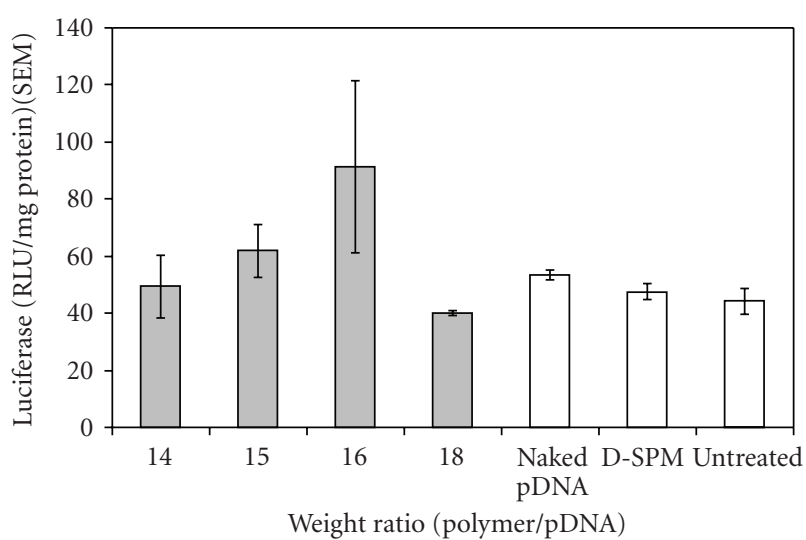

FIGURE 5: Luciferase expression (RLU/mg protein) in the trachea and lung of $\mathrm{BALB} / \mathrm{c}$ mice following administration of naked pCIKLux, dextran-spermine only (D-SPM), and various weightmixing ratios of D-SPM/pCIKlux complexes ranging 14 to 18 at 2 days posttreatment. The amount of DNA was kept to $10 \mu \mathrm{g}$. Untreated mice was served as the control. Data are presented as mean \pm S.E.M from 6 animals.

there might be a likelihood of the D-SPM/pDNA complexes to be removed by the reticuloendothelial system from the capillaries in the lung, which resulted in the inefficiency of specific targeting capability of the polycation to the lung epithelial cells. Next is from the aspect of the interaction between the complexes with the serum proteins such as albumin, albeit low in the lung, might increase the tendency of the DNA release and eventually reduced the interaction between the intact DNA with target cells [31].

3.4. Reporter Gene Expression Time Point Profile. For the previous experiments, all the luciferase assays were done at 2 days post-treatment, as suggested in the luciferase assay protocol (Promega, USA). Evaluations of the luciferase expression for D-SPM were also performed at 2 days posttreatment by Hosseinkhani et al. [28], which exhibited optimum transfection efficiency. However, in this study, the

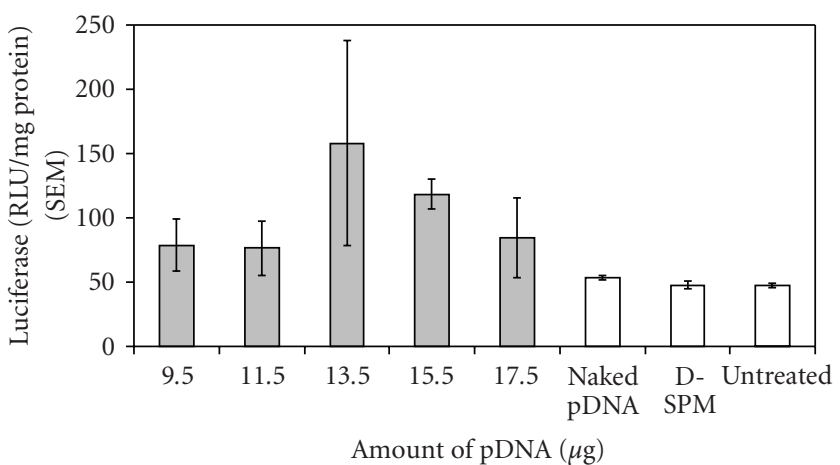

FIGURE 6: Luciferase expression (RLU/mg protein) in the trachea and lung of $\mathrm{BALB} / \mathrm{c}$ mice following the administration of D-SPM complexed with different amount of pCIKLux, at 2 days posttreatment. The w/w ratio was kept at 16 . Untreated mice were served as the control. Data are presented as mean \pm S.E.M from 6 animals.

target cells for gene delivery were different, and therefore after all the parameters including the weight-mixing ratios and amount of pDNA of D-SPM/pDNA for maximal reporter gene expression have been optimized, there was a need to determine the time point when the level of gene expression was at its peak.

Based on the study carried out by Wei et al. [48] which reported that $6 \mathrm{~h}$ duration was adequate for carrier/pDNA complex to enter the cells in vitro, a minimum time of $6 \mathrm{~h}$ was selected to sacrifice the mice. Conversely, the maximum time point of seven days was chosen as the level of reporter gene expression by a nonviral vector would normally reach negligible value by day 4 postinstillation [38]. Thus, a time point profile study over a period of seven days was carried out in this study.

As the amount of pDNA of the D-SPM/pDNA complex was $13.5 \mu \mathrm{g}$ showed the highest reporter gene expression, subsequent experiments employed this amount of pDNA, while the w/w ratio was kept to 16 . The D-SPM/pDNA complexes were administered to each mouse, and the animals were sacrificed at several time points within a week. At $6 \mathrm{~h}$ postadministration, the level of luciferase activity was negligible (Figure 7, filled squares). Maximum gene expression was detected at day 1 with luciferase reading at $274.6 \pm 109.8 \mathrm{RLU} / \mathrm{mg}$ lung protein, dropped markedly, and eventually reached insignificant value by day 2 . These results show that airway gene expression mediated by $\mathrm{D}$ $\mathrm{SPM} / \mathrm{pDNA}$ was transient. The transient phenomenon may be attributed to the transcriptional inactivation of the cytomegalovirus (CMV) promoter used in pCIKLux in this study. It was reported that this strong viral promoter confers high level of gene expression in vivo but does not direct persistent transgene expression and undergoes promoter attenuation in response to inflammatory-mediated cytokines $[49,50]$. Since the highest reporter gene expression level was detected at day 1 postadministration, the following experiments were performed using D-SPM/pDNA at w/w ratio 16 , with $13.5 \mu \mathrm{g}$ pDNA where the mice were sacrificed at day 1 postadministration. 


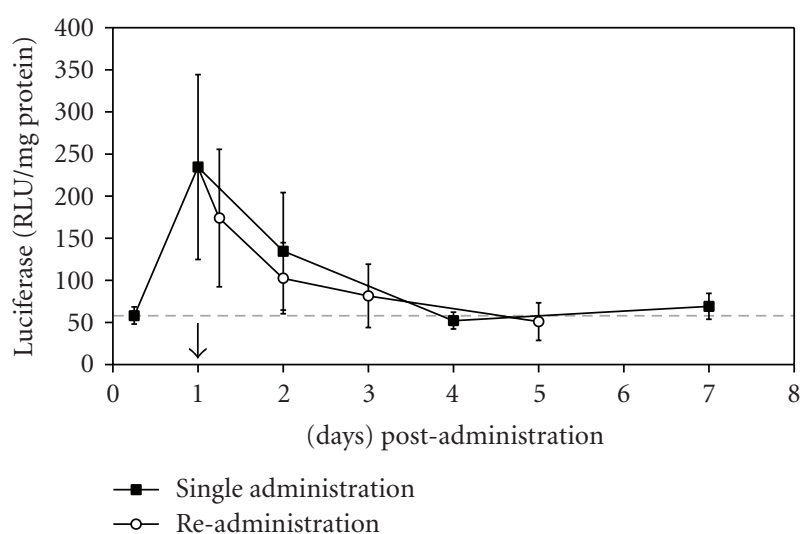

FIgURE 7: Luciferase expression (RLU/mg protein) in the trachea and lung of $\mathrm{BALB} / \mathrm{c}$ mice following the administration of $\mathrm{D}$ $\mathrm{SPM} / \mathrm{pDNA}$ at ratio 16 , containing $13.5 \mu \mathrm{g}$ pDNA with succeeding readministration post $24 \mathrm{~h}$ of first dosing. The vertical arrow pointing downward indicates the time point of readministration after the initial administration. The horizontal dash line represents the approximate sensitivity of the assay. Data are presented as mean \pm S.E.M from 6 animals.

3.5. Repeat Administration of D-SPM/pDNA to the Mouse Airways. One of the fundamental challenges in gene therapy is the persistent transgene expression. However, D-SPM/pDNA administration with plasmid controlled by CMV promoter only resulted in a transient reporter gene expression. One way to increase the duration as well as to maintain the level of transgene expression is by repeating the administrations of the therapeutic gene. It has been proven that repeat administrations of the therapeutic gene are critical in treating chronic lung diseases, which require lifelong treatment such as cystic fibrosis, asthma, and emphysema [51]. Hence, repeat administration of the D-SPM/pDNA study was performed to evaluate if this procedure could have a positive effect on the duration of reporter gene expression.

In this study, another dose of D-SPM/pDNA (at w/w ratio of 16 and pDNA amount of $13.5 \mu \mathrm{g}$ ) was administered to the mice at day 1 postinitial administration. The level of luciferase activities were measured at $6 \mathrm{~h}, 1$ day, 2 days, and 4 days post readministration. The highest reporter gene expression was detected at 6-hour post readministration (174.1 $\pm 81.6 \mathrm{RLU} / \mathrm{mg}$ lung protein) but dropped markedly to insignificant level by day 1 post readministration (Figure 7, open circles). This clearly shows that repeated administration of D-SPM/pDNA did not augment the first administration to enhance or even to restore the luciferase activity.

Readministration of D-SPM/pDNA might result in the increased amount of the complexes, which could inadvertently interact with the serum protein in the lungs. Accumulation of the aggregates of D-SPM/pDNA and serum protein could entrap the pDNA inside the complex by impeding the disassociation of the pDNA from the DSPM, after its uptake into the cells' cytoplasm. The reduced number of free pDNA in the nucleus of the targeted cell is reflected by the decreased level of reporter gene activity [52]. On another paper, the effect of repeated anaesthesia on mouse and the development of neutralizing antibody to the luciferase protein could probably contribute to the reduced luciferase activity of the second dosing [53]. It is expected that the readministration of the D-SPM with pDNA carrying reporter gene other than luciferase, following the initial administration of D-SPM/pCIKLux, will show a better level of gene expression due to the absence of existing neutralizing antibody against the second reporter gene [28, 47].

Other investigators have also reported the inefficiency of the repeated administrations by nonviral vectors in vivo. Griesenbach and Alton [54] observed that the expression of the transgene was reduced and eventually absent from the cell even after more than 2 repeated administrations of the gene delivery complex. Earlier observations by Wiseman et al. [53] showed that repeated dosing of linear $22 \mathrm{kDa}$ polyethylenimine PEI failed to provide higher reporter gene activity as compared to the initial dose. Almost similar result was obtained from the study done by Orson et al. [55], which highlighted that repeated intravenous administration of the same dose of protein/PEI/pDNA complexes encoding luciferase reporter gene was unsuccessful in increasing the luciferase activity.

\section{Conclusion}

This paper demonstrates that dextran-spermine (D-SPM) gene delivery into the lung resulted in modest level of reporter gene expression as compared to the control animals. $\mathrm{D}-\mathrm{SPM} / \mathrm{pDNA}$ exhibited transient gene expression in the mouse lung with no significant improvement on the level or persistency of gene expression following readministration of the complex. We also showed that the D-SPM/pDNA complex was formed within a nanometer range. The inability of the polymer to efficiently protect the DNA from degradation by DNase I shown here probably translates to the low transfection efficiency seen in the lungs as the complex might not be able to shield the pDNA against the effects of the endogenous nucleases. Taken together, this study suggests that further work needs to focus on increasing the transfection efficiency of the D-SPM. This could be done by modifying the physiochemical properties of the D-SPM, such as the particle charge and aggregation tendency to mimic the chemical properties of a highly efficient nonviral gene delivery agent available in the market. In addition, the evaluation on the safety profiles of D-SPM as a gene carrier to the lung, which has not been performed in this study, should be conducted to complement the reporter gene expression results.

\section{Acknowledgments}

The authors would like to thank the Universiti Putra Malaysia New Lecturers (5315823) and Research University (04/01/07/0123RU) Grant schemes for the financial supports. They thank Ira-Yudovin Farber for her technical assistance in the preparation of the dextran-spermine. S. Abdullah and W. Y. Wendy-Yeo are equally contributing to the paper. 


\section{References}

[1] T. R. Flotte and B. J. Carter, "Adeno-associated virus vectors for gene therapy of cystic fibrosis," Methods in Enzymology, vol. 292, pp. 717-732, 1998.

[2] A. G. Schatzlein, "Non-viral vectors in cancer gene therapy: principles and progress," Anti-Cancer Drugs, vol. 12, no. 4, pp. 275-304, 2001.

[3] D. Liu, T. Ren, and X. Gao, "Cationic transfection lipids," Current Medicinal Chemistry, vol. 10, no. 14, pp. 1307-1315, 2003.

[4] G. R. Rettig and K. G. Rice, "Non-viral gene delivery: from the needle to the nucleus," Expert Opinion on Biological Therapy, vol. 7, no. 6, pp. 799-808, 2007.

[5] T. Montier, T. Benvegnu, P.-A. Jaffrès, J.-J. Yaouanc, and P. Lehn, "Progress in cationic lipid-mediated gene transfection: a series of bioinspired lipids as an example," Current Gene Therapy, vol. 8, no. 5, pp. 296-312, 2008.

[6] J. Haensler and F. C. Szoka Jr., "Polyamidoamine cascade polymers mediate efficient transfection of cells in culture," Bioconjugate Chemistry, vol. 4, no. 5, pp. 372-379, 1993.

[7] A. G. Schatzlein, B. H. Zinselmeyer, A. Elouzi et al., "Preferential liver gene expression with polypropylenimine dendrimers," Journal of Controlled Release, vol. 101, no. 1-3, pp. 247-258, 2005.

[8] G. Y. Wu and C. H. Wu, "Receptor-mediated gene delivery and expression in vivo," Journal of Biological Chemistry, vol. 263, no. 29, pp. 14621-14624, 1988.

[9] O. Boussif, F. Lezoualc'h, M. A. Zanta et al., "A versatile vector for gene and oligonucleotide transfer into cells in culture and in vivo: polyethylenimine," Proceedings of the National Academy of Sciences of the United States of America, vol. 92, no. 16, pp. 7297-7301, 1995.

[10] D. Goula, J. S. Remy, P. Erbacher et al., "Size, diffusibility and transfection performance of linear PEI/DNA complexes in the mouse central nervous system," Gene Therapy, vol. 5, no. 5, pp. 712-717, 1998.

[11] S. Venkatesh and T. J. Smith, "Chitosan-mediated transfection of HeLa cells," Pharmaceutical Development and Technology, vol. 2, no. 4, pp. 417-418, 1997.

[12] P. Erbacher, S. Zou, T. Bettinger, A.-M. Steffan, and J.S. Remy, "Chitosan-based vector/DNA complexes for gene delivery: biophysical characteristics and transfection ability," Pharmaceutical Research, vol. 15, no. 9, pp. 1332-1339, 1998.

[13] D. Balicki and E. Beutler, "Histone H2A significantly enhances in vitro DNA transfection," Molecular Medicine, vol. 3, no. 11, pp. 782-787, 1997.

[14] Y. J. Park, J. F. Liang, K. S. Ko, S. W. Kim, and V. C. Yang, "Low molecular weight protamine as an efficient and nontoxic gene carrier: in vitro study," Journal of Gene Medicine, vol. 5, no. 8, pp. 700-711, 2003.

[15] T. Takai and H. Ohmori, "DNA transfection of mouse lymphoid cells by the combination of DEAE-dextran-mediated DNA uptake and osmotic shock procedure," Biochimica et Biophysica Acta, vol. 1048, no. 1, pp. 105-109, 1990.

[16] M. Nishikawa and L. Huang, "Nonviral vectors in the new millennium: delivery barriers in gene transfer," Human Gene Therapy, vol. 12, no. 8, pp. 861-870, 2001.

[17] W. T. Godbey, K. K. Wu, and A. G. Mikos, "Size matters: molecular weight affects the efficiency of poly(ethylenimine) as a gene delivery vehicle," Journal of Biomedical Materials Research, vol. 45, no. 3, pp. 268-275, 1999.
[18] R. Kircheis, L. Wightman, and E. Wagner, "Design and gene delivery activity of modified polyethylenimines," Advanced Drug Delivery Reviews, vol. 53, no. 3, pp. 341-358, 2001.

[19] T. Bieber and H.-P. Elsässer, "Preparation of a low molecular weight polyethylenimine for efficient cell transfection," BioTechniques, vol. 30, no. 1, pp. 74-81, 2001.

[20] H. Hosseinkhani, Y. Inatsugu, Y. Hiraoka, S. Inoue, H. Shimokawa, and Y. Tabata, "Impregnation of plasmid DNA into three-dimensional scaffolds and medium perfusion enhance in vitro DNA expression of mesenchymal stem cells," Tissue Engineering, vol. 11, no. 9-10, pp. 1459-1475, 2005.

[21] H. Hosseinkhani and M. Hosseinkhan, "Biodegradable polymer-metal complexes for gene and drug delivery," Current Drug Safety, vol. 4, no. 1, pp. 79-83, 2009.

[22] H. Hosseinkhani, M. Yamamoto, Y. Inatsugu et al., "Enhanced ectopic bone formation using a combination of plasmid DNA impregnation into 3-D scaffold and bioreactor perfusion culture," Biomaterials, vol. 27, no. 8, pp. 1387-1398, 2006.

[23] H. Hosseinkhani, T. Azzam, H. Kobayashi et al., "Combination of 3D tissue engineered scaffold and non-viral gene carrier enhance in vitro DNA expression of mesenchymal stem cells," Biomaterials, vol. 27, no. 23, pp. 4269-4278, 2006.

[24] H. Hosseinkhani, M. Hosseinkhani, N. P. Gabrielson, D. W. Pack, A. Khademhosseini, and H. Kobayashi, "DNA nanoparticles encapsulated in 3D tissue-engineered scaffolds enhance osteogenic differentiation of mesenchymal stem cells," Journal of Biomedical Materials Research A, vol. 85, no. 1, pp. 47-60, 2008.

[25] H. Hosseinkhani, T. Kushibiki, K. Matsumoto, T. Nakamura, and Y. Tabata, "Enhanced suppression of tumor growth using a combination of NK4 plasmid DNA-PEG engrafted cationized dextran complex and ultrasound irradiation," Cancer Gene Therapy, vol. 13, no. 5, pp. 479-489, 2006.

[26] T. Azzam, H. Eliyahu, L. Shapira, M. Linial, Y. Barenholz, and A. J. Domb, "Polysaccharide-oligoamine based conjugates for gene delivery," Journal of Medicinal Chemistry, vol. 45, no. 9, pp. 1817-1824, 2002.

[27] T. Azzam, H. Eliyahu, A. Makovitzki, M. Linial, and A. J. Domb, "Hydrophobized dextran-spermine conjugate as potential vector for in vitro gene transfection," Journal of Controlled Release, vol. 96, no. 2, pp. 309-323, 2004.

[28] H. Hosseinkhani, T. Azzam, Y. Tabata, and A. J. Domb, "Dextran-spermine polycation: an efficient nonviral vector for in vitro and in vivo gene transfection," Gene Therapy, vol. 11, no. 2, pp. 194-203, 2004.

[29] H. Hosseinkhani, T. Aoyama, O. Ogawa, and Y. Tabata, "Tumor targeting of gene expression through metalcoordinated conjugation with dextran," Journal of Controlled Release, vol. 88, no. 2, pp. 297-312, 2003.

[30] H. Eliyahu, A. Makovitzki, T. Azzam et al., "Novel dextranspermine conjugates as transfecting agents: comparing watersoluble and micellar polymers," Gene Therapy, vol. 12, no. 6, pp. 494-503, 2005.

[31] H. Eliyahu, A. Joseph, J. P. Schillemans, T. Azzam, A. J. Domb, and Y. Barenholz, "Characterization and in vivo performance of dextran-spermine polyplexes and DOTAP/cholesterol lipoplexes administered locally and systemically," Biomaterials, vol. 28, no. 14, pp. 2339-2349, 2007.

[32] M. Ogris, S. Brunner, S. Schüller, R. Kircheis, and E. Wagner, "PEGylated DNA/transferrin-PEI complexes: reduced interaction with blood components, extended circulation in blood and potential for systemic gene delivery," Gene Therapy, vol. 6, no. 4, pp. 595-605, 1999. 
[33] D. Papahadjopoulos, T. M. Allen, A. Gabizon et al., "Sterically stabilized liposomes: improvements in pharmacokinetics and antitumor therapeutic efficacy," Proceedings of the National Academy of Sciences of the United States of America, vol. 88, no. 24, pp. 11460-11464, 1991.

[34] U. Griesenbach, A. Chonn, R. Cassady et al., "Comparison between intratracheal and intravenous administration of liposome-DNA complexes for cystic fibrosis lung gene therapy," Gene Therapy, vol. 5, no. 2, pp. 181-188, 1998.

[35] J. L. Rau, "The inhalation of drugs: advantages and problems," Respiratory Care, vol. 50, no. 3, pp. 367-382, 2005.

[36] J. West and D. M. Rodman, "Gene therapy for pulmonary diseases," Chest, vol. 119, no. 2, pp. 613-617, 2001.

[37] D. J. Weiss, "Delivery of gene transfer vectors to lung: obstacles and the role of adjunct techniques for airway administration," Molecular Therapy, vol. 6, no. 2, pp. 148-152, 2002.

[38] D. R. Gill, S. E. Smyth, C. A. Goddard et al., "Increased persistence of lung gene expression using plasmids containing the ubiquitin $\mathrm{C}$ or elongation factor $1 \alpha$ promoter," Gene Therapy, vol. 8, no. 20, pp. 1539-1546, 2001.

[39] E. R. Lee, J. Marshall, C. S. Siegel et al., "Detailed analysis of structures and formulations of cationic lipids for efficient gene transfer to the lung," Human Gene Therapy, vol. 7, no. 14, pp. 1701-1717, 1996.

[40] J.-I. Jo and Y. Tabata, "Non-viral gene transfection technologies for genetic engineering of stem cells," European Journal of Pharmaceutics and Biopharmaceutics, vol. 68, no. 1, pp. 90104, 2008.

[41] I. Yudovin-Farber and A. J. Domb, "Cationic polysaccharides for gene delivery," Materials Science and Engineering C, vol. 27, no. 3, pp. 595-598, 2007.

[42] G. L. Lukacs, P. Haggie, O. Seksek, D. Lechardeur, N. Freedman, and A. S. Verkman, "Size-dependent DNA mobility in cytoplasm and nucleus," Journal of Biological Chemistry, vol. 275, no. 3, pp. 1625-1629, 2000.

[43] J. Chen, B. Tian, X. Yin et al., "Preparation, characterization and transfection efficiency of cationic PEGylated PLA nanoparticles as gene delivery systems," Journal of Biotechnology, vol. 130, no. 2, pp. 107-113, 2007.

[44] Y. Zhang, Y. Zhang, J. Chen et al., "Polybutylcyanoacrylate nanoparticles as novel vectors in cancer gene therapy," Nanomedicine, vol. 3, no. 2, pp. 144-153, 2007.

[45] S. Nimesh, A. Goyal, V. Pawar et al., "Polyethylenimine nanoparticles as efficient transfecting agents for mammalian cells," Journal of Controlled Release, vol. 110, no. 2, pp. 457468, 2006.

[46] G. Kaul and M. Amiji, "Tumor-targeted gene delivery using poly(ethylene glycol)-modified gelatin nanoparticles: in vitro and in vivo studies," Pharmaceutical Research, vol. 22, no. 6, pp. 951-961, 2005.

[47] H. Hosseinkhani and Y. Tabata, "Ultrasound enhances in vivo tumor expression of plasmid DNA by PEG-introduced cationized dextran," Journal of Controlled Release, vol. 108, no. 2-3, pp. 540-556, 2005.

[48] J.-Z. Wei, L. Lin, W. Xiong, and Q.-Y. Zhu, "Transfection with a novel cationic gene carrier: PEI-PBLG," Chinese Journal of Biotechnology, vol. 23, no. 2, pp. 228-234, 2007.

[49] R. S. Sung, L. Qin, and J. S. Bromberg, "TNF $\alpha$ and IFN $\gamma$ induced by innate anti-adenoviral immune responses inhibit adenovirus-mediated transgene expression," Molecular Therapy, vol. 3, no. 5, part 1, pp. 757-767, 2001.

[50] L. Qin, Y. Ding, D. R. Pahud, E. Chang, M. J. Imperiale, and J. S. Bromberg, "Promoter attenuation in gene therapy: interferon- $\gamma$ and tumor necrosis factor- $\alpha$ inhibit transgene expression," Human Gene Therapy, vol. 8, no. 17, pp. 20192029, 1997.

[51] I. P. Hall, "How will genetic approaches assist in the management of respiratory diseases?" Current Opinion in Pharmacology, vol. 9, no. 3, pp. 256-261, 2009.

[52] D. V. Schaffer, N. A. Fidelman, N. Dan, and D. A. Lauffenburger, "Vector unpacking as a potential barrier for receptor-mediated polyplex gene delivery," Biotechnology and Bioengineering, vol. 67, no. 5, pp. 598-606, 2000.

[53] J. W. Wiseman, C. A. Goddard, D. McLelland, and W. H. Colledge, "A comparison of linear and branched polyethylenimine (PEI) with DCChol/DOPE liposomes for gene delivery to epithelial cells in vitro and in vivo," Gene Therapy, vol. 10, no. 19, pp. 1654-1662, 2003.

[54] U. Griesenbach and E. W. F. W. Alton, "Gene transfer to the lung: lessons learned from more than 2 decades of CF gene therapy," Advanced Drug Delivery Reviews, vol. 61, no. 2, pp. 128-139, 2009.

[55] F. M. Orson, L. Song, A. Gautam, C. L. Densmore, B. S. Bhogal, and B. M. Kinsey, "Gene delivery to the lung using protein/polyethylenimine/plasmid complexes," Gene Therapy, vol. 9, no. 7, pp. 463-471, 2002. 

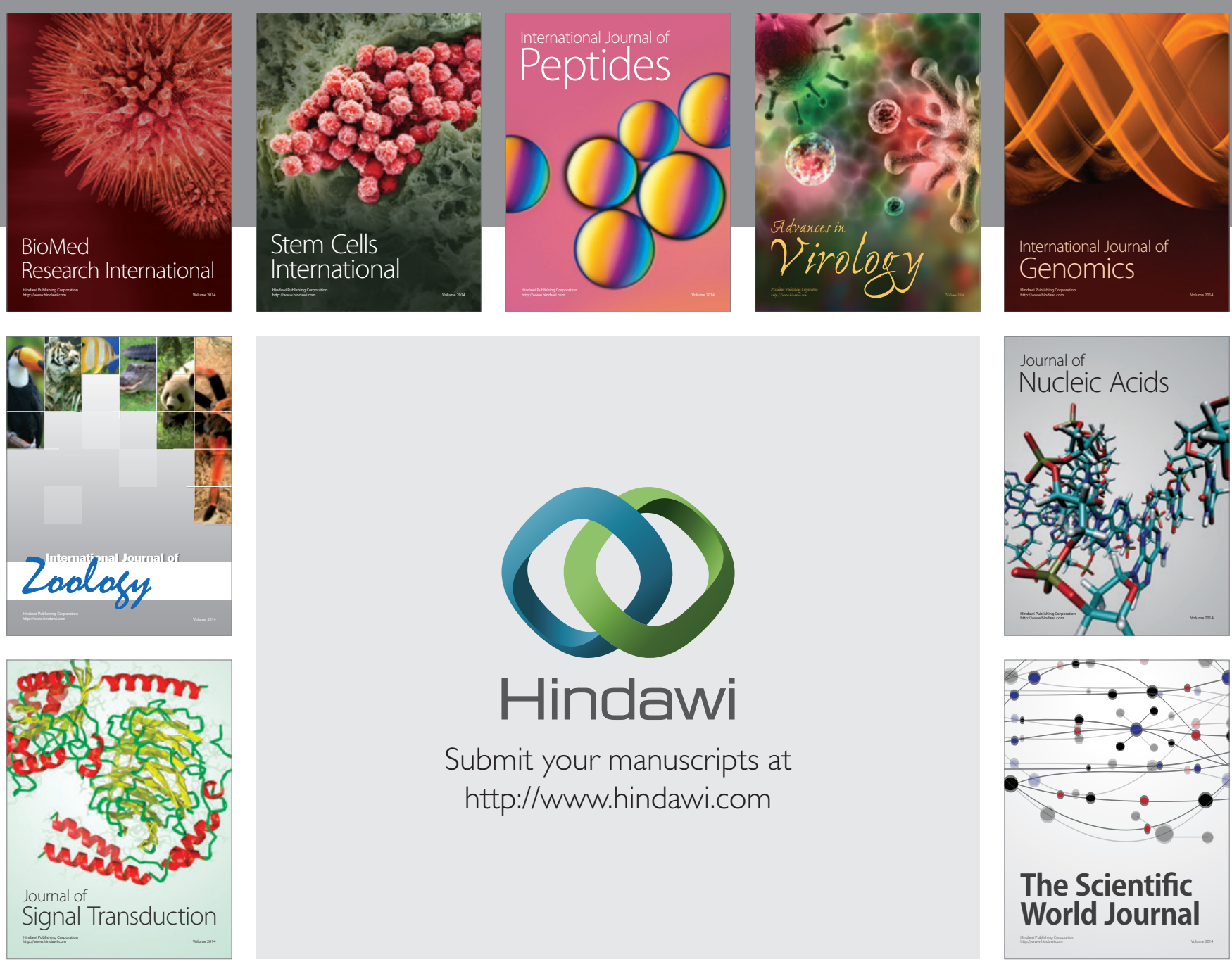

Submit your manuscripts at

http://www.hindawi.com
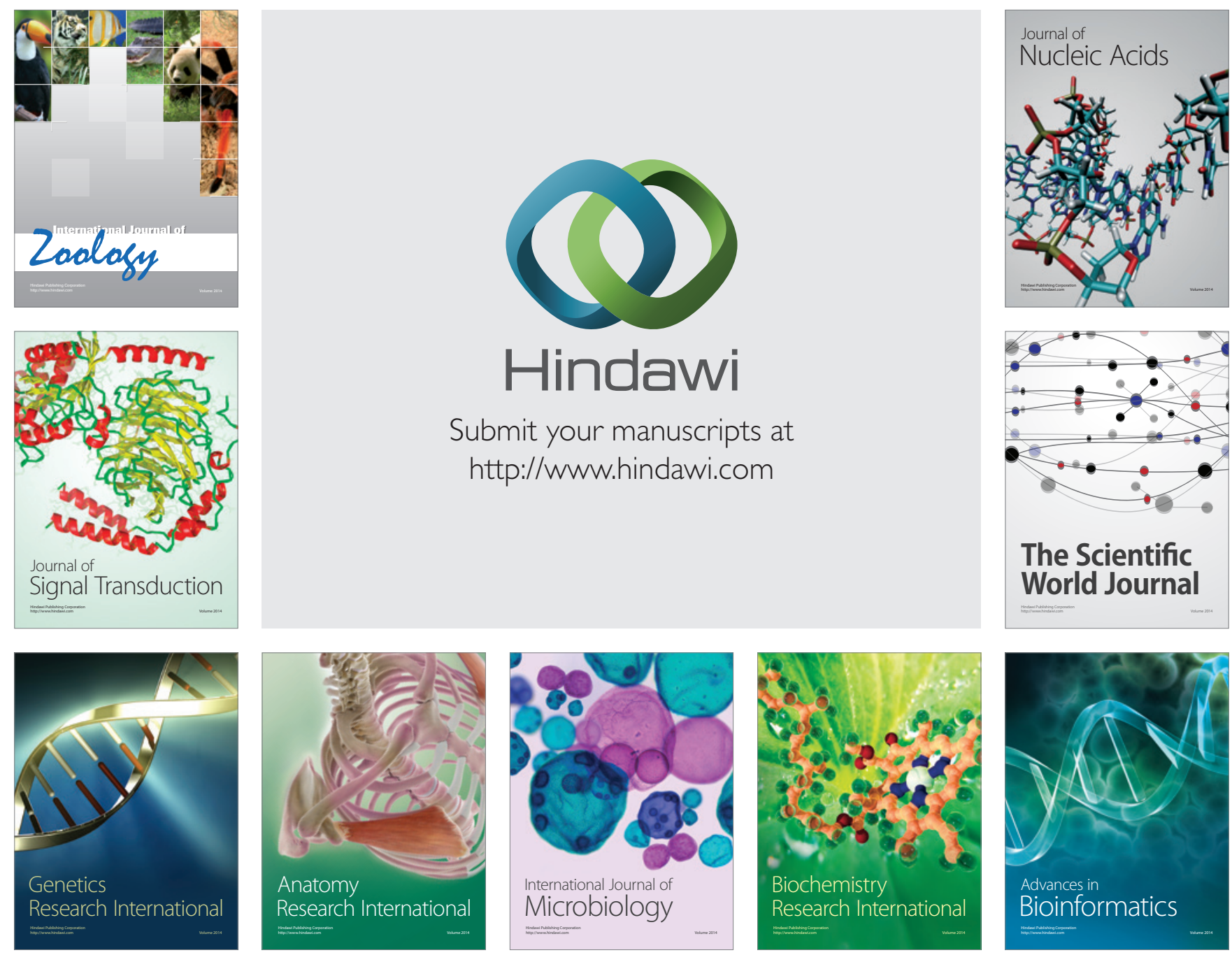

The Scientific World Journal
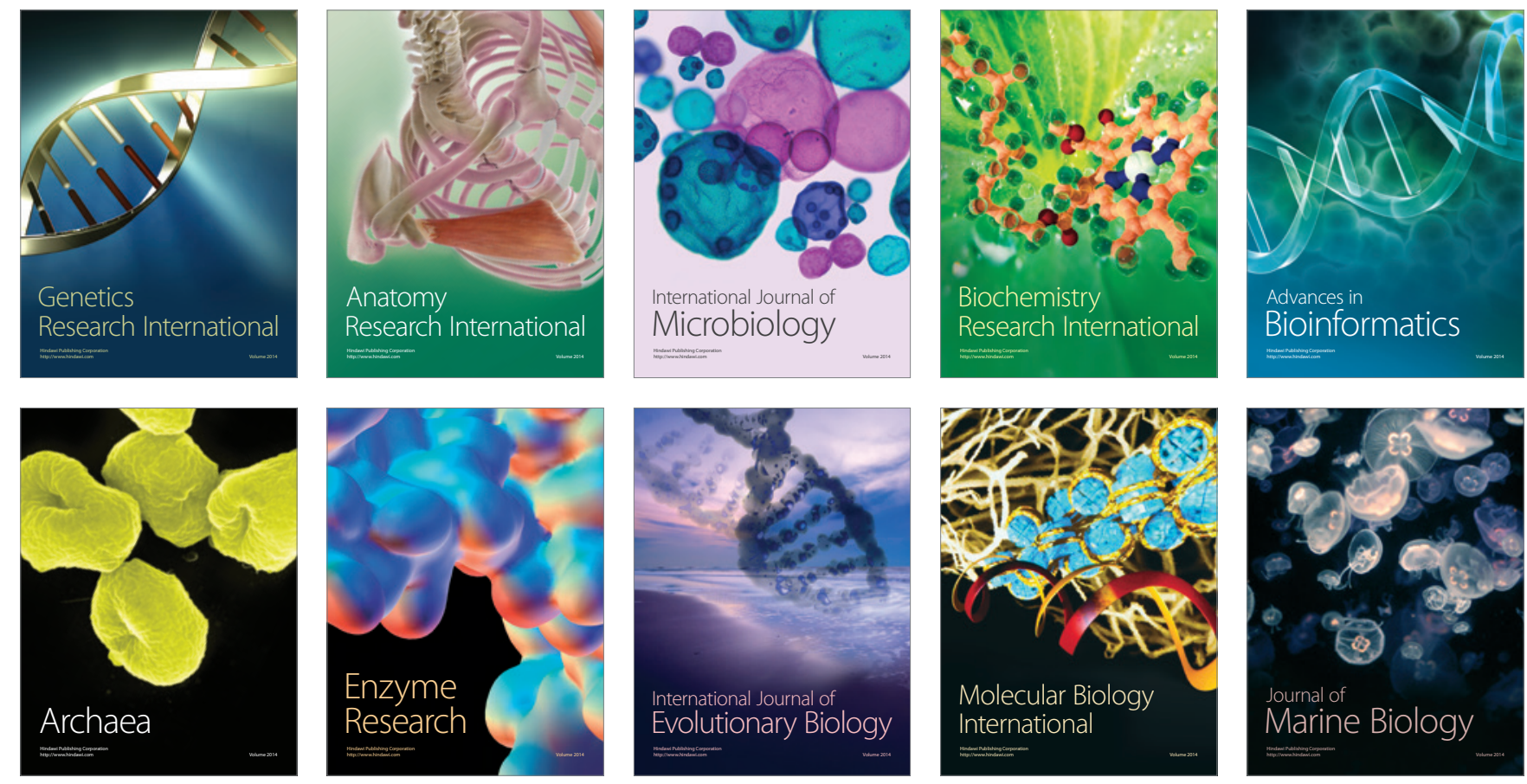